\title{
Especial
}

\section{CRIATIVIDADE E COMUNICAÇÃO INTERCULTURAL CÊNICA}

\author{
CREATIVITY AND SCENIC \\ INTERCULTURAL COMMUNICATION
}

CREATIVIDAD Y COMUNICACIÓN INTERCULTURAL ESCÉNICA

Inaicyra Falcão dos Santos

Inaicyra Falcão dos Santos Professora doutora livre-docente do Instituto de Artes da Universidade Estadual de Campinas. 


\section{Resumo}

As limitações conceituais acerca da dança afro ou, como a considero, africano-brasileira se devem às bases epistemológicas hegemônicas constituídas oficialmente, as quais não fornecem referenciais que difundam a diversidade artística em seus distintos aspectos e contextos. Nessa vivência, delineio a trilha concebida na tese de doutorado Corpo e ancestralidade - cuja proposta indica possibilidades de pesquisa e criação nas artes cênicas e na educação, a partir da relação entre a arte e a tradição africano-brasileira. Nessa conjunção, proponho trilhas que entrelaçam estudo, ensino e processo criativo, e, sobretudo, destaco novas possibilidades para os ensinamentos ancestrais africanos no entendimento mais amplo da comunicação intercultural na contemporaneidade.

Palavras-chave: Arte, Dança, Educação, Memória.

\section{Abstract}

The conceptual limitations concerning the African dance or, as I consider it, African-Brazilian are resulted from officially established epistemological hegemonic bases, which do not provide references that diffuse artistic diversity in its different aspects and contexts. In this experience, I delineate the path suggested by Corpo e ancestralidade, whose proposal indicates possibilities for research and creation in the performing arts and education, based on the relationship between art and the African-Brazilian tradition. In this conjuncture, I propose paths that intertwine study, teaching, and creative process, and, above all, I highlight new possibilities for the ancestral African teachings in the broader understanding of intercultural communication in contemporary times.

Keywords: Art, Dance, Education, Memory. 


\section{Resumen}

Las limitaciones conceptuales del baile afro o como lo considero africano-brasileño son ocasionadas por las bases epistemológicas hegemónicas construidas oficialmente, que no contribuyen con la difusión de la diversidad artística en sus distintos aspectos y contextos. En este contexto, sigo la discusión planteada en la tesis de doctorado Corpo e ancestralidade, cuja propuesta indica posibilidades de investigación, de creación en las artes escénicas y en la educación desde la relación entre arte y tradición africana-brasileña. En este sentido, propongo establecer relaciones entre estudio, enseñanza y proceso creativo, sobre todo de nuevas posibilidades para las enseñanzas ancestrales africanas desde los aportes más amplios de comunicación intercultural en la contemporaneidad.

Palabras clave: Arte, Baile, Educación, Memoria.

\section{Arte africano-brasileira}

O complexo cultural negro-africano, que dá sustentação à cultura africano-brasileira, recria uma particular visão de mundo e de expressão de todo um universo simbólico de valores. As comunidades-terreiro representam o centro organizador da comunicação, que é estabelecida por meio de gestos, sons, exclamações, ritmos, cores e formas que se constituem numa linguagem que veicula pela atividade individual e grupal a continuidade da tradição, desse modo,

é bom esclarecer que quando falo de tradição não me refiro a algo congelado, estático que aponta apenas à anterioridade ou antiguidade, mas aos princípios míticos inaugurais, constitutivos e condutores de identidade, memória, capazes de transmitir de geração a geração continuidade essencial e ao mesmo tempo, reelaborar-se nas diversas circunstâncias históricas, incorporando informações estéticas que permitam renovar a experiência, fortalecendo seus próprios valores. (SANTOS, 1989, p. 1)

Desde cedo, a ênfase dessas inferências e o envolvimento nesse ambiente foram experiências basilares em nossa subjetividade e formação pessoal, que conduziram trajetórias particulares de visões e condutas na sociedade global em relação ao que foi concebido como dança afro. 
Compreender essa dança é complexo, reverberação do corpo negro, do corpo estigmatizado. Em cena, ele é ao mesmo tempo agente e produto de sua obra de arte. Dessa forma, o conflito é estabelecido e assim tem sido entendido pelo poder hegemônico, algo que é considerado de segunda classe por apresentar identificadores diferentes dos oficialmente reconhecidos.

Por outro lado, ao examinarmos detidamente, notamos e constatamos que não existem posicionamentos comuns a respeito do que é dança afro. Existe, por parte da maioria dos artistas negros, uma busca de ocupação de espaço, de reivindicação de lugar na sociedade, perante ideologias conservadoras produzidas pelos posseiros dos códigos culturais no país, os quais resistem em não reconhecer sabedorias das realidades plurais dos brasileiros. Essa concordância acaba por constituir fortemente um cenário de incompreensão, que na maioria das vezes desqualifica a expressão por falta de informação para abalizar as artes expressas com outros próprios códigos e características físicas.

No entanto, entendo que a dança afro se apresenta atualmente como expressão estética, afinal, são diversas as concepções criativas na sociedade brasileira. As abordagens têm sido construídas, nas últimas décadas, tanto na concepção e história quanto na coreografia de forma múltipla, diferenciada. Pode-se considerar como a própria história da dança moderna na América. Existe um ponto de vista e múltiplas experiências.

Portanto, considero que a dança afro pós-colonial é aquela que deixou de representar exclusivamente as danças religiosas dos orixás e ampliou suas referências, enraizada tanto nas culturas dos negros brasileiros, africanos e afrodescendentes quanto nos corpos negros dos bailarinos e simpatizantes. No que concerne aos temas, podem ser referências tradicionais, sócio-políticas, dramas vividos no cotidiano pelos negros nas cidades grandes, danças de países africanos e de sociedades remotas. As vivências de seus líderes e participantes são fundamentais na concepção da obra. $O$ treinamento corporal tem sido aprimorado cada vez mais por diversas linguagens de dança, lutas e técnicas. O hibridismo é evidenciado devido ao avanço tecnológico, à globalização, e se tornou realidade para todos; bailarinos com vivências e referenciais múltiplos; pesquisas; e viagens que geram novas possibilidades de vocabulário corporal e enriquecem o processo coreográfico e o conhecimento do tema. Em suma, a dança fica relacionada às poéticas individuais de cada 
criador, sempre apresentando uma configuração adjetivada como os conceitos afro ou negra contemporânea.

Diante dessas assertivas, podemos levantar uma questão significativa: a cada dia os negros da sociedade brasileira se tornam mais conscientes. Os movimentos sociais, históricos e políticos da realidade que se vive no país se tornaram elementos constitutivos para a visão dessa dança.

É interessante ressaltar que, em função do crescimento de cursos de graduação e pós-graduação em dança e artes cênicas no país, o debate tem-se intensificado devido às inúmeras reinvindicações de estudantes negros inseridos nesses espaços. As contestações inspiradas pelos discursos de representantes de outras áreas, relacionadas à natureza da dança, comumente carecem de teorias. Dessa forma, são respaldadas, a partir de áreas como educação, antropologia, sociologia e outras que trazem esclarecimentos, reflexões que permitem aprofundar e considerar as sabedorias dos povos que deram forma à cultura do país. Ou seja, é preciso inserir nos currículos uma abordagem pluricultural e interdisciplinar sobre as artes com suas sabedorias, histórias e culturas.

\section{Memória e identidade}

Vivendo e participando do cenário mencionado, com a família, formação em dança e como intérprete, aspirei desenvolver um trabalho para além dessa realidade movida por uma ótica da tradição cultural do indivíduo, aquela construída com um olhar mais ampliado de respeito, para além de uma arte rotulada pela cor da pele ou pela incapacidade de conhecimento.

Fatores pontuais vivenciados foram fundamentais, sempre que me apresentava fora dos identificadores reconhecidos como arte na dança euro-americana, era considerada como bailarina afro, enquanto minha habilitação foi em Dançarino Profissional. Intuí que jamais poderia me desligar dessa realidade se quisesse me expressar, dizer algo dentro do meu entendimento. Os movimentos da coreografia por estar no meu corpo negro, como intérprete, atravessado por aspectos da dominação, do poder colonizador, dos mitos e estereótipos, impediam a sociedade de ver além-mundo. Essa atitude, como já mencionei, constitui o cenário de como a percepção do corpo negro é visto no contexto hegemônico. 
Outro fator preciso foi o tema. As mitologias têm influenciado os artistas desde os primórdios e esteve presente nos trabalhos dos pioneiros, isto é, os criadores da dança moderna, a mitologia grega. Esse conhecimento veio a impulsionar a temática da mitologia ioruba, como tema de pesquisa e criação, em meu percurso artístico.

Essas constatações foram propiciadas pela oportunidade que tive no curso de graduação em Dança, na Universidade Federal da Bahia. Fui aluna do coreógrafo e bailarino Clyde Morgan, seus ensinamentos e presença foram norteadores para minha narrativa enquanto artista. Considero como momento especial quando ele nos mostrou vídeos de coreografias da Companhia de Dança do coreógrafo, também negro, Alvin Ailey. Surgia com esse aprendizado um caminho para a arte - foi enriquecedor ter assistido a primeira bailarina da companhia da época, Judith Jamison, no solo Cry e a coreografia Revelations.

Nessa trajetória de busca, espaço e tempo se cruzam; ao chegar aos Estados Unidos, queria conhecer como era desenvolvido o trabalho corporal da companhia do coreógrafo Alvin Ailey. Pensava que eles desenvolviam uma técnica direcionada aos corpos negros e para minha surpresa não existia nada especial. Eram as técnicas de clássico e moderno que eu já tinha estudado, a novidade foi a técnica de Lester Horton, mestre de Alvin Ailey, que incorporou danças indígenas americanas à sua técnica.

Naquele centro cultural de Nova lorque, pude também desenvolver pesquisas nas bibliotecas sobre história da dança e biografias de seus grandes nomes, principalmente sobre suas investigações na arte da dança.

Esses estudos foram fundamentais, contribuíram significativamente para a consolidação da minha identidade, ofereceram meios de rever processos formadores, localizar minha posição na arte da dança e a indicar trajetórias e conceitos sobre as vivências artísticas.

The vision of modern dance, do editor Jean Morrison Brown (1979), foi crucial nessa trajetória. Constitui-se por filosofias de trabalho de nomes significativos da dança americana, bailarinos coreógrafos com suas histórias e seus questionamentos sociais. Além disso, também apresenta pontos de vista, proferidos individualmente, sobre as diversas possibilidades da dança moderna, era dividido em fases históricas, desde o início do movimento, com Isadora Duncan, até a nova dança de vanguarda. Esta encerrava o livro com 
um texto crucial do coreógrafo negro Rod Rodgers, "Don't tell me who I am" ("não me diga quem eu sou", tradução livre), com o seguinte trecho:

A minha negritude é parte da minha identidade como ser humano e minha expressão e desenvolvimento na dança é o resultado da minha experiência total com homem. É simplesmente uma questão do que precede no ato criativo: se é minha total experiência como ser vivente, ou se aquelas experiências as quais eu considero relevantes para minha negritude. (RODGERS apud BROWN, 1979, p. 175)

Essa afirmação de Rod Rodgers se tornou uma realidade anos depois quando realizei e interpretei a coreografia Raízes, considerada "clássica" para um público formado por pessoas negras, no Teatro na Universidade de Ibadan, Nigéria, enquanto foi apreciada como "afro" no Teatro Bela Vista em Salvador, Brasil.

O último ponto significativo foi quando li a comunicação, apresentada na exposição Les magiciens de la Terre, no Centre Pompidou de Paris em 1989, do artista, sacerdote, educador e escritor Deoscóredes M. dos Santos (Mestre Didi):

A primeira vez que fizeram um cartaz fotografando uma de minhas esculturas que tinha ganho um dos primeiros prêmios na Bienal da Bahia, os produtores do cartaz, um órgão de turismo não só colocaram o nome da escultura 'objeto folclórico da Bahia', mas também meu nome foi atribuído como artesão. Fiquei pensando, por que essa dificuldade em admitir meu trabalho, mesmo que premiado na Bienal, como obra de arte.

Esse pensamento me fornecia conhecimentos múltiplos. Como intérprete, queria me expressar, contribuir para o cenário da arte e da educação no Brasil. Queria compreender abordagens originais analíticas das sabedorias da tradição africano-brasileira, para inseri-las na inexistência de propostas dessa natureza. Parecia necessário mostrar outra visão de mundo, que não a sustentada por ideologias racionalistas, mas que indica distintas possibilidades, a fim de um entendimento amplo nas sociedades plurais contemporâneas. Havia chegado o momento, como escreveu Tarkovski (1990, p. 49) "é errado dizer que o artista 'procura' o seu tema. Este na verdade, amadurece dentro dele como um fruto, e começa a exigir uma forma de expressão. É como um parto". 
Assim, com a finalidade de aprofundar as informações mencionadas, o desenvolvimento conceitual se originou. Seu enfoque seria conduzir o estudo como uma proposta criativa coreográfica, com a mitologia ioruba. Instigada, durante a pesquisa de campo sobre um dos mitos da origem do tambor batá, entre os iorubas em Oyó, na Nigéria, elaborei o roteiro em forma de poema, o qual coreografei e interpretei Ayán (símbolo do fogo).

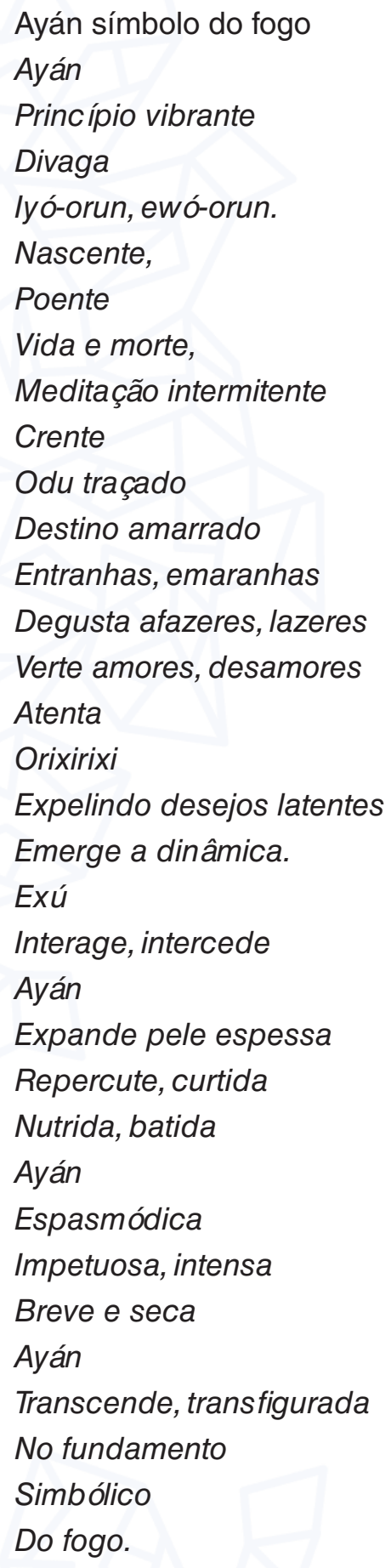


No processo de criação, foram assimilados aspectos intelectuais e coreográficos, analogias, o que culminou aspectos para o conteúdo de Corpo e ancestralidade (SANTOS, 2014). A obra norteou, sobretudo, a personalidade da personagem Ayán e o suporte enfático-melódico do ritmo batá, produzido pelos descendentes dos iorubas, nos terreiros nagô, na cidade de Salvador (BA), Brasil. Enquanto o vocabulário coreográfico foi incorporado da qualidade estilística do batá da cidade de Oyó, na Nigéria. A experiência transformou-se e adquiriu forma nova, configurou a origem de uma trilha norteadora de pesquisa, expressão artística e proposta educacional no cenário da dança brasileira.

Seria importante pensar na tradição africano-brasileira, na composição de formas expressivas e na dança como criação artística. Deveria ser necessária a retomada dos valores culturais das identidades em questão. Era importante percebê-las como celeiro portador de ideias, como agente de integração que pode estabelecer uma coerência; uma organicidade entre a tradição cultural, o conhecimento da arte teorizado, como revitalização e possibilidades de enriquecimento da cultura e atividades voltadas para a arte e educação.

\section{Fundamentos}

A dimensão artístico-educacional em Corpo e ancestralidade (SANTOS, 2014) abriu espaço para um pensamento que busca adentrar essa diversidade cultural brasileira com o intuito de trazer elementos de referência na formação do cotidiano do sujeito e seu entorno. Está registrada em sua filosofia a perspectiva intercultural como multiplicidade étnica e estratégia de identidade cultural brasileira, tanto na dança como em arte e educação.

Outro aspecto a se considerar é a questão da ancestralidade integrante de todo ser humano, todas as culturas, e que nas formas africano-brasileiras é o alicerce de ação, de fundamento estruturante e vigoroso em sua forma de existir. A ancestralidade nos dirige para a origem, recinto de práticas culturais nas quais se instituem estruturações de comunidades de representação a partir da convivência grupal e de suas particularidades culturais vivenciadas como elementos inspiradores do respeito e da convivência humana. É importante destacar que se propõem trilhas do saber do homem, a comunicação significativa entre conhecimentos empíricos e científicos na arte; refletem os 
princípios inaugurais, mitos, símbolos, dinâmica de criação e recriação, estabelecendo a relação entre tradição e contemporaneidade. Sobre narrativa mítica, Andraus (2014, p. 22)

Consideramos que a investigação da própria bagagem mítica configura um caminho seguro para a construção de um discurso poético coerente para o bailarino, minimizando os riscos de ele, quando ainda jovem ou inexperiente, perder-se diante da pluralidade de referencias de estilos. Trata-se de uma proposta centrada no sujeito e que ao mesmo tempo leva em consideração as influências que ele recebe de seu contexto.

A dinâmica metodológica de campo se caracteriza pela dimensão da perspectiva "desde dentro para fora, desde fora para dentro", ou seja, o envolvimento de imersão no contexto da pesquisa, assim, convêm esclarecer que

a experiência participativa "iniciática" significa aprender os elementos e valores de uma cultura "desde dentro" mediante uma inter-relação dinâmica no seio do grupo, e ao mesmo tempo poder abstrair dessa realidade empírica os mecanismos do conjunto e seus significados dinâmicos, suas relações simbólicas em uma abstração consciente "desde fora". (SANTOS, 1996, p. 18)

A decodificação de elementos simbólicos, a pesquisa e as abstrações serão integradas à fisicalidade e ao processo criativo. Serão realizadas no despertar de uma identidade de elementos, que a poética concretiza na experiência humana, isto é, no corpo, o qual é portador da vivência, da expressão e da comunicação. A sucessão dos passos abarca o conhecimento do corpo, a compreensão de significados e conteúdos, a história pessoal, a pesquisa e a reflexão crítica das vivências. Essa preparação corporal visa aprofundar o conhecimento, ampliar o domínio sobre os movimentos e estimular o potencial criativo dos intérpretes. Também busca o fortalecimento da identidade cultural, da capacitação profissional e da possibilidade de compreensão quanto a possíveis contribuições à sociedade e cuida dos valores culturalmente adquiridos.

Considera-se a cultura, na criação artística, como a natureza humana, a tradição de cada um por meio da dança, da encenação, do canto e das imagens. Pretende-se que esses elementos sejam desdobrados na realidade dos participantes cujo resultado é um trabalho artístico acompanhado de reflexão 
crítica sobre ele. A trama interdisciplinar entrelaça os participantes no trabalho de construção cênica, com interpretação dos conteúdos simbólicos, estruturais e culturais. A memória possibilita a percepção de vivências passadas, lembranças referentes ao passado de cada um. Essas narrativas corporais são geradas pelas ações físicas acompanhadas de um sentido. Dessa forma, define-se um estado dinâmico a partir do qual os personagens são criados, com uma dramaturgia pessoal que renova e reconstrói um passado mítico, cujo conteúdo corporal é expresso por meio de redes tecidas na multiplicidade de significações, que transcende na contemporaneidade com uma identidade própria e abre caminho para outros olhares.

As vivências citadas, nascidas de um estado de abertura com a proposta, possibilitam o "momento" de imersão mais profunda do intérprete, do seu universo, da habilidade da pesquisa, no contexto da arte-interpretativa com uma visão de mundo e, a partir disso, torna-se possível dar forma a algo novo.

Esse processo é articulado em duas direções: de um lado, a ênfase nas representações sensíveis da cultura africano-brasileira; de outro, o aprofundamento de uma abordagem criativa artística interdisciplinar. Tudo isso associado a uma história pessoal, cuja concepção é desenvolvida com discernimento ético, unido ao objetivo de fazer essa arte de forma integrada. Evidencia-se, na prática, com a filosofia que intitulei de etno-crono-ética. $\mathrm{O}$ alicerce é o "homem", a relação humana, o respeito ao outro, às diferenças e a si próprio. Assumir atitude etno-crono-ética revela que existe outra noção de tempo e espaço. É se valer de sua própria percepção dinâmica, emergir no próprio corpo e mostrar este corpo e, assim, existe memória, movimento e história. É despertar, ainda, para a necessidade do cuidado com as ações individuais, atividade própria do intérprete, a partir de suas possibilidades dentro do conteúdo proposto. A importância desse olhar é a vivência e o respeito à diversidade plural da qual fazemos parte; é desmistificar estereótipos, ampliar horizontes, apontando, assim, para um espaço de valorização das relações saudáveis. O conteúdo e a obra gerada tomam forma na sensibilização, percepção e conscientização do corpo; nas ações corporais ancestrais e textos míticos. Essa perspectiva se desdobra em uma série de consequências, entre as quais cumpre destacar: 
1. Percepção corporal, isto é, tomar consciência da própria estrutura, do próprio esqueleto e de suas articulações, a partir de alongamento musculares;

2. Exercícios corporais e vocais a partir de matrizes tradicionais de danças e ações cotidianas a fim de perceber e analisar qualidades dos elementos do movimento expressivo;

3. Experimentação corporal de novos espaços e percepção gestual; recortar, fragmentar, dar espaço para que outros caminhos atravessem o corpo; rearticulação de novas possibilidades e conexões inéditas entre as partes do corpo; investigação de outros trajetos de movimentos, assim abstraindo códigos adquiridos;

4. Criação cênica, que é o momento de síntese, da relação com as experiências vivenciadas e as histórias individuais. Corpos que se reconfiguram, trazendo neles impressa a passagem do tempo. O corpo contemporâneo compõe uma inovação da experiência e, assim, percebe-se por meio de uma linguagem artística criada a presentificação e a renovação de mitos de origem.

Diante do exposto, constata-se que o percurso pode ser entendido como um processo formativo e criativo nos desdobramentos de uma visão interdisciplinar, com uma configuração intertextual a partir das tradições, nesse caso a africano-brasileira e a arte da dança cênica. Centra-se na importância do sensível, do corpo do intérprete-bailarino. Considera-se o movimento como processo constante de gerar outras possibilidades de organização do corpo, permitindo diferentes modos de expressão e comunicação. Cito dois trechos que ampliam a experiência narrada:

Isto faz do trabalho da Profa Dra Inaicyra Falcão dos Santos uma proposta pluricultural (ou seja, que leva em consideração a formação pluriétnica do brasileiro) de dança arte educação (a dança aqui entendida como processo no desenvolvimento do individuo). Existe ainda nesta proposta, a ideia de ancestralidade, ou seja, o argumento de que certos movimentos são arquetípicos e estão presentes na movimentação do homem desde tempos imemoriais. (ANDRAUS, 2014, p. 24)

E completa:

Há ainda, nesta proposta, o conceito "porteira para dentro, porteira para fora", cunhado pela ialorixá Maria Bibiana do Espírito Santo, que no contexto original (da vida dentro dos cultos da tradição iorubá), significa 
separar a vivência pessoal daquela vivida no espaço religioso ou terreiro, e na proposta da Profa. Inaicyra significa que, da porteira para fora, está-se se falando em reelaboração estética dos elementos rituais, e nunca na transposição do ritual para o palco. (Ibid., p. 23)

Quando exponho esse discurso, reflito sobre experiências passadas e verifico a importância de informar pontos significativos dos elementos constitutivos ao leitor. Mostro que a experiência estética é característica significativa nessa herança estética vivida na comunidade-terreiro e familiar, que me iniciou com música, dança, poesia, escultura, mitos, ritmos, culinária, cenografia, bem como a artístico-acadêmica. Essas experiências me enriqueceram profissionalmente, afirmaram-me como ser humano, nutriram minha autoestima, proporcionaram-me sabedoria. Tornaram-me capaz de dar continuidade a essa tradição como "afirmação existencial", "expandiu fronteiras", transpôs o local, o gueto - espaços que nos é facilmente permitido pela cultura dominante.

\section{Reflexões}

Na trilha de Corpo e ancestralidade (SANTOS, 2014), instala-se uma transcendência que está intimamente ligada ao ato de criação presente na arte e na cultura à medida que transforma ideias, conceitos e atitudes. As experiências mostram mais uma possibilidade de conhecimento de pesquisa, criação e interpretação artística, que se realiza a partir de princípios inaugurais de uma tradição, cuja dinâmica expande e aponta para o entendimento da arte com o africanismo brasileiro e cujo produto não se desvincula dos valores ancestrais, recebidos de determinada cultura e, ao mesmo tempo, encontra caminhos múltiplos de expressão na contemporaneidade.

Assim, está criticamente em convivência com outras perspectivas de desenvolvimento e de produção de reflexão teórica e epistemológica sobre a formação, especialmente voltada para o campo da arte e do ensino.

Carrega conhecimento e cultura, estabelecendo uma dialética entre as memórias e desvelando concepções artísticas e estéticas plurais. Experiência que compreende as mitologias negras, populares, indígenas e assim por diante. O sensível permeia o reencontro do indivíduo consigo mesmo, com 
sua ancestralidade, e o impulsiona para um mundo mais ético, criativo, plural e humano.

\section{Referências bibliográficas}

ANDRAUS, M. B. M. Arte marcial na formação do artista da cena. Jundiaí: Paco, 2014.

BROWN, J. M. The vision of modern dance. Trenton: Princeton Book, 1979.

SANTOS, D. M. Tradição e contemporaneidade. In: COLOQUIO MAGICIENS DE LA TERRE, 1989, Paris. Procédures... Paris: Musée National d’Art Moderne/Centre Georges Pompidou, 1989.

SANTOS, I. F. Da tradição africana brasileira a uma proposta pluricultural de dança-arte-educação. 1996. 203 p. Tese (Doutorado em Educação) - Faculdade de Educação, Universidade de São Paulo, São Paulo, 1996.

Corpo e ancestralidade: uma proposta pluricultural de dança-arte-educação. 3. ed. São Paulo: Terceira Margem, 2014.

TARKOVSKI, A. Esculpir o tempo. São Paulo: Martins Fontes, 1990.

Recebido em 26/06/2017

Aprovado em 26/06/2017

Publicado em 05/09/2017 